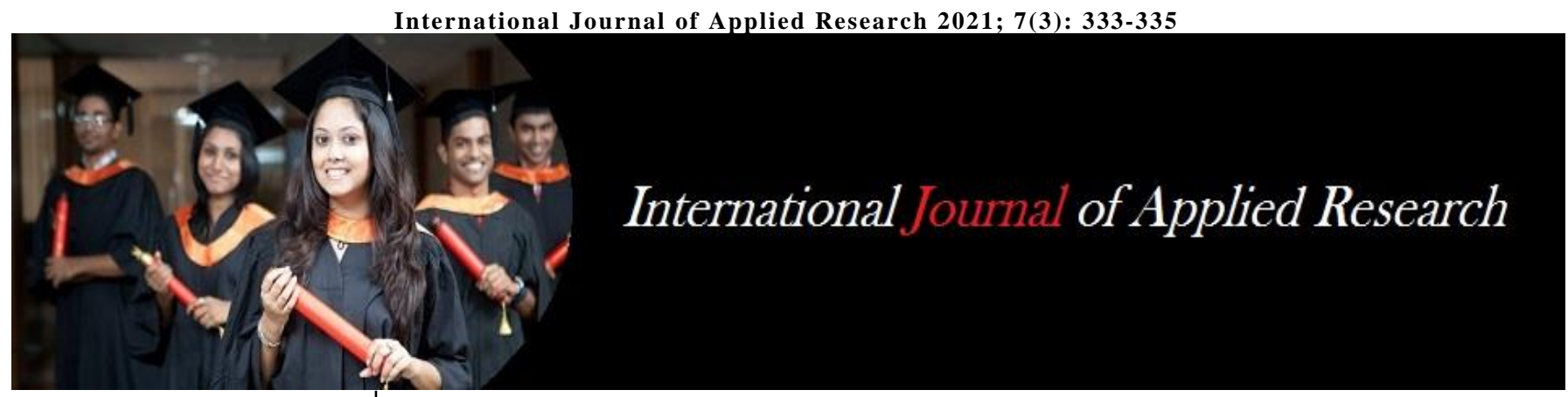

ISSN Print: 2394-7500

ISSN Online: 2394-5869

Impact Factor: 8.4

IJAR 2021; 7(3): 333-335

www.allresearchjournal.com

Received: 01-01-2021

Accepted: 03-02-202

Rimsha Rashid

M.Sc Nursing, Community

Health Nursing, Bharati

Vidyapeeth (Deemed to be

University) College of Nursing,

Pune, Maharashtra, India

Sunita Chavan

Clinical Instructor,

Community Health Nursing,

Bharati Vidyapeeth (Deemed

to be University) College of

Nursing, Pune, Maharashtra,

India
Corresponding Author:

Rimsha Rashid

M.Sc Nursing, Community

Health Nursing, Bharati

Vidyapeeth (Deemed to be

University) College of Nursing,

Pune, Maharashtra, India

\section{A study to assess attitude and barriers regarding use of community health bag among nursing teachers in selected nursing colleges at Pune city}

\author{
Rimsha Rashid and Sunita Chavan
}

DOI: https://doi.org/10.22271/allresearch.2021.v7.i3f.8421

\section{Abstract}

Title: Assess attitude and barriers regarding use of community health bag among Nursing teachers. Objectives: Measure attitude regarding use of community health bag and identify barriers for limited use of community health bag.

Materials and Methods: Quantitative research approach with descriptive research design were used for this study. Non-probability purposive sampling technique was used for the samples of 60 Nursing teachers. Each samples age, Qualification, Experience of work was recorded. Attitude and barriers was assessed with Rating scale and self-structured Opinionare which included opinion regarding barriers, modifications in the community health bag and use of community health bag. Descriptive and inferential statistics were used in data analysis. The findings of the rating scale were associated with the demographic variables.

Result: The findings revealed that majority $35 \%$ belonged to the of $>35$ year of age group, $80 \%$ of sample were Masters in Nursing, 33\% the participants were with 3-5 years of experience, majority 54 (93.50\%) of nursing teachers have Positive Attitude regarding use of community health bag. The demographic variable of qualification found an association with attitude as the calculated chi square value (20.35) was greater than chi square table value (7.82). Other variable Age and Experience were calculated less than chi square table value so there is no association.

Conclusion: In this study the sample having higher qualification had positive attitude regarding use of community health bag. Also certain barriers were identified by the sample and suggestions were given for the modification of bag. Thus it is necessary to remove the barriers and modify the community health bag to make it more acceptable.

Keywords: nursing teachers, attitude, barriers, modifications, opinion, measure, identify

\section{Introduction}

The use of community health was started during the time of Florence nightingale to meet the needs of people and provide basic care at their home. This bag has changed a lot over the years from the black leather Nursing bag that was carried by Lillian Wald during his home visits during early $20^{\text {th }}$ century in the Henry street settlement to the present bag carried by the Nursing personals and other health care providers containing different compartments and is highly modified ${ }^{[1]}$. It is a key apparatus that is vital to the work of a community Nurse.

\section{Need of the study}

The bag technique is an easy and affordable technique for the prevention of cross-infection between various families. It is like a small portable hospital ward ${ }^{[5]}$. McGoldrick (2014) conducted a study about bag technique and measures to prevent and control infection in home settings. Community health bag is used to prevent the spread of infection from one family to another in home settings. Matt Vera (2012) conducted a study on bag technique in Nursing where he listed many benefits of using this bag during home. He said the bag technique may not prevent the spread of infection but it will definitely minimize the spread of infection. Use of community health bag saves time and efforts in the performance of Nursing procedures ${ }^{[2]}$.

Being a researcher and a student of Master in Nursing, researcher has selected this topic because of her personal experience in Community area. It is vital to know the attitude of nursing teachers towards community health bag in order to find the reason of the declining use of community health bag. 


\section{Objectives of the study}

- To measure attitude regarding use of community health bag.

- To identify barriers for limited use of community health bag.

- To identify various modifications that can be done in community health bag

- To assess the opinion related to the use of community health bag.

- To associate the findings of attitude with the demographic data.

\section{Methodology}

Research Approach: A Quantitative Approach

Research Design: Descriptive Method.

Research Settings: selected Nursing Colleges of Pune City

Population: Nursing teachers in any Nursing college of Pune city.

Sample: Nursing teachers from community health Nursing department teaching in any Nursing college of Pune city.

\section{Criteria for Sample Selection}

Inclusion criteria

- Qualification: Ph.D., Msc Nursing, Bsc Nursing, PbBsc Nursing

- Experience: Minimum 3 years experience in teaching institute

- Age: 25 \& above

- Department: Those who are working in community health Nursing department

\section{Exclusion Criteria}

- Recently passed teachers with basic Bsc Nursing, PbBsc Nursing and GNM

Sample Size: 60

Sampling Technique: Non-probability purposive sampling technique

Data Collection Tool consist of Personal characteristics of samples, assessment of attitude of sample regarding use of Community health bag, assessment of barriers faced by sample while using Community health bag, assessment of suggestions given by sample for modification of community health bag and assessment of opinion of sample regarding use of community health bag.

\section{Results}

\section{Findings of sample characteristics}

Majority $35 \%$ belonged to the of $>35$ year of age group, $33.33 \%$ belonged to $31-35$-year of age group and $31.66 \%$ participants were in the age group of 25-30 year.

Findings also depicts that Majority of participants $80 \%$ were MSc Nursing and $8.5 \%$ participants were with PhD Nursing and $6.5 \%$ participants were with BSc Nursing and 5\% participants were with PbBSc Nursing.

Regarding experience, $33 \%$ the participants were with 3-5 years, $26.5 \%$ participate having 6-7 year of experience, $23 \%$ having $>10$ years of experience, and $16.5 \%$ participants were 8-10 years of work experience
Findings related to attitude regarding use of community health bag among nursing teachers

Table 1: Shows the attitude of nursing teachers regarding the use of community bag

\begin{tabular}{|c|c|c|c|}
\hline \multicolumn{4}{c}{ Attitude score } \\
$\mathrm{n}=60$ \\
\hline & Positive & Negative & Total \\
\hline Frequency & 56 & 4 & 60 \\
\hline Percentage & $93.50 \%$ & $6.50 \%$ & 100 \\
\hline
\end{tabular}

Table 1: shows the attitude of nursing teachers regarding the use of community bag revels that majority $54(93.50 \%)$ of nursing teachers have Positive Attitude and 4 (6.50\%) nursing teachers have Negative attitude regarding use of community health bag.

Findings related to identify barriers for limited use of community health bag

On analysis following of responses, following barriers were identified by the respondents:

- $60 \%$ said that availablity of water for hand washing and equipment cleaning.

- $45 \%$ said that improper handling of the bag.

- $66 \%$ said difficult to maintain sterility during procedures.

- $24 \%$ said inability to perform each and every step due to difficulty in managing the bag at the home of a client.

- $72 \%$ said difficulty of maintaining cleanliness of articles at home of client is a barrier.

- $34 \%$ said in some cases bag cannot be cleaned on daily basis.

- $\quad 42 \%$ said regular autoclaving is not possible.

- $84 \%$ said old pratices is still used like spirit lamp.

- $67 \%$ said hygiene and sterility cannot be maintained due to continues travelling.

- $56 \%$ said weight of bag is a barrier because it is difficult to carry.

- $46 \%$ said disposal of water after procedure is sometimes a barrier in the use of bag.

Findings related to identify various modifications that can be done in community health bag

After analysis certain modification were suggested by the subjects that could be done in community health bag

- $\quad 84 \%$ said old generation articles like sprit lamp can be removed because its old generation and now some other good options are available like urostrips for glucose in urine.

- $56 \%$ that medication like anti- pyretic and painkillers for regular treatment can be added with standard guidelines.

- $85 \%$ said that Community health bag is used in rural areas mostly so according to availability of health services a delivery kit can be added.

- $60 \%$ said that Disposable articles can be used to maintain aseptic technique

- $86 \%$ said that Can be update with new latest articles like digital thermometer and digital sphygmomanometer

- $\quad 92 \%$ said that Hand sanitizer can be added to maintain aseptic technique 
- $84 \%$ said that Separate pockets for articles

- $56 \%$ said that Urine analysis strip or dipstick can be added

- $\quad 42 \%$ said that advanced or digital Hb kit can be added

- $\quad 92 \%$ said that Weight can be reduced so it will be easy to carry

- $\quad 89 \%$ said that Water proof bag can be replaced with old bag so it can be easy to wash

Findings related to assess the opinion related to the use of community health bag

After analysis various opinions were given by the respondents about the community health bag:

$78 \%$ of my sample said it is very important to use community bag during home visits. $89 \%$ of my sample said we should continue to use community health bag in home visiting. $83 \%$ of my sample agreed upon the fact that the community bag has not been given due acknowledgement. $83 \%$ of my sample said it is very important for a nurse to protect herself from infection while using a community health bag. $83 \%$ of my sample said that daily use of community health bag will enhance health services in the community area. $83 \%$ of my sample said it is very important for a nurse to protect herself from infection while using a community health bag. $100 \%$ of my sample have opinion that there is no replacement for community health bag but some modifications should be done. $50 \%$ of my sample agreed that community health bag saves time and effort in the performance of nursing procedure.

Findings related to association of demographic data with attitude regarding use of community health bag among nursing teachers

Only one variable; the demographic variable of qualification found an association with attitude as the calculated chi square value i.e. 20.35 was greater than chi square table value 7.82. Other variable Age and Experience were calculated less than chi square table value so there is no association.

\section{Acknowledgement}

We will like to extend our sincere gratitude to all the participants for taking part in our study and making this study a success. We will also like to thank all the concerned authorities for granting us permission to conduct this research.

\section{Discussion}

The researcher had studied community health Nursing from her bachelor's in Nursing where she learnt about the community health bag and its importance. The researcher had attended a lot of community posting where she observed that community health bag is not used in a way it should be used. Thus the researcher thought of identifying the attitude of Nursing teachers towards use of this bag as the teachers are responsible to shape the mind of students, also researcher wanted to identify barriers for using this bag, modifications that can be done in the bag and opinion of Nursing teachers on use of community health bag.

\section{Conclusion}

The conclusion drawn from the study is as follows:

The title of the study was "A study to assess attitude and barriers regarding use of community health bag among nursing teachers in selected nursing colleges of Pune city. "Chi" square test was used to see the association of attitude with different set demographic variables. Only one variable; the demographic variable of qualification found an association with attitude as the calculated i.e. 20.35 was greater than chi square table value 7.82. Other variable Age and Experience were calculated less than chi square table value so there is no association. Majority of the Nursing teachers had positive attitude towards the use of community health bag. The barriers for limited use of community health bag got different responses from the subjects with $50 \%$ of all the subjects responded by saying that the community bag carried old generation articles like spirit lamp and it is difficult to carry while $100 \%$ of the subjects responded saying community bag has got no replacement but some modifications needed to be done.

\section{References}

1. Bag_Technique_Preventing_and_Controlling@ journals.lww.com [Internet]. Available from: https://journals.lww.com/homehealthcarenurseonline/F ulltext/2014/01000/Bag_Technique_Preventing_and_ Controlling.6.aspx

2. 3a656351cd88f5597f5296c38be1e6d510fe81ec@ nurseslabs.com [Internet]. Available from: https://nurseslabs.com/home-visits-bag-technique/

3.8e9096ac2c936a8959ddcbba8b819d8d5c2aac52@ www.allheart.com [Internet]. Available from: https://www.allheart.com/blog/sa/b-nursing-bagtechnique/

4. 8bd71159880fc686062a3e988a1773ff79056405 @ www.hopkinsmedicalproducts.com [Internet].

Available from:

https://www.hopkinsmedicalproducts.com/service/a/ho me-health-bag-technique-best-practice/

5. d189a548a446093949a26331ebf6886874478b3a@ slideplayer.com [Internet]. Available from: https://slideplayer.com/slide/12926720/

6. 3-essential-tips-for-your-nursing-bag-technique@ blog.bayada.com [Internet]. Available from: https://blog.bayada.com/work-life/3-essential-tips-foryour-nursing-bag-technique

7. conceptual-framework @ systemsinnovation.io [Internet]. Available from: https://systemsinnovation.io/conceptual-framework

8. Health_belief_model @ en.wikipedia.org [Internet]. Available from:

https://en.wikipedia.org/wiki/Health_belief_model

9. Navdeep kaur brar $\mathrm{H}$ rawat. A textbook of advanced nursing practice [Internet]. ist. jaypee; 696-709 p. Available from:

https://www.jaypeebrothers.com/pgDetails.aspx?book_i $\mathrm{d}=9789351522010$

10.6426380@www.ncbi.nlm.nih.gov [Internet]. Available from: https://www.ncbi.nlm.nih.gov/pubmed/6426380 